\title{
RETROSPECTIVE MULTICENTRIC STUDY ON THE POST-SURGERY SYMPTOMATIC AND OBJECTIVE IMPROVEMENT OF BENIGN PROSTATIC HYPERPLASIA PATIENTS
}

\author{
NEERAJ GUPTA ${ }^{1 *}$, SUNIL KUMAR MAINI ${ }^{1}$, VISHNU PAL ${ }^{2}$, PUNIT TIWARI ${ }^{3}$, LOYA BM ${ }^{4}$ \\ ${ }^{1}$ Department of Surgery, RKDF Medical College, Bhopal, Madhya Pradesh, India. ${ }^{2}$ Department of Anatomy, People's College of Medical \\ Sciences and Research Centre, Bhopal, Madhya Pradesh, India. ${ }^{3}$ Department of MKM Stone and Urology Centre, Bhopal, Madhya \\ Pradesh, India. ${ }^{4}$ Department of Surgery, Mahaveer Institute of Medical Sciences and Research, Bhopal, Madhya Pradesh, India. \\ Email: neeraj5378@gmail.com
}

Received: 09 March 2021, Revised and Accepted: 14 July 2021

\section{ABSTRACT}

Aims and Objectives: To evaluate patients of benign prostatic hyperplasia (BPH) preoperatively and identify those who would benefit from surgery, to evaluate outcome of surgery for BPH with respect to symptomatic and objective improvement of patients, and to compare the results of different surgeries for BPH being done different hospitals at Bhopal, which included transurethral resection of the prostate (TURP), transurethral incision of prostate (TUIP)/bladder neck incision (BNI), and Freyer's prostatectomy?

Methods: The present study was carried out at different hospitals of Bhopal. Patients presenting to the surgery outpatient department with symptoms of obstruction, namely, weak urinary stream, frequency hesitancy, intermittency, urgency, nocturia, etc., were included in the study. Some of the subjects included were patients presenting during emergency timings with complaints of retention of urine or occasionally other symptoms. The American Urological Association (AUA) Symptom Index questionnaire was administered to all such patients. They were also evaluated by ultrasound examination and patients having BPH on ultrasound (USG) were further evaluated by uroflowmetry.

Results: Prostatic weight correlated well with the maximum urinary flow rates with an inverse relationship. Both maximum and average urinary flow rates (Q max and Qav) were improved by all the three surgeries However, TURP and Freyer's prostatectomy showed greater improvement as compared to TUIP/BNI. Combination of AUA scoring, USG, and uroflowmetry helped us document improvement in our BPH patients and compared it favorably with other studies.

Conclusion: Uroflowmetry was a simple assessment tool easy to learn and use. It was also inexpensive and formed a useful extension to clinical examination providing objective evidence of obstruction. It also helped to indirectly quantity the severity of obstruction. Symptom severity did not correlate with prostate size. Small prostates caused symptoms in the severe range also while even large prostates sometimes caused little symptoms. Prostatic weight correlated well with the maximum urinary flow rates with an inverse relationship

Keywords: Benign prostatic hyperplasia, Freyer's prostatectomy, Uroflowmetry, Prostatectomy.

(c) 2021 The Authors. Published by Innovare Academic Sciences Pvt Ltd. This is an open access article under the CC BY license (http://creativecommons.org/ licenses/by/4.0/) DOI: http://dx.doi.org/10.22159/ajpcr.2021v14i8.41357. Journal homepage: https://innovareacademics.in/journals/index.php/ajpcr

\section{INTRODUCTION}

Benign prostatic hyperplasia (BPH) is the most common disorder affecting the prostate gland [1]. It is a major cause of morbidity in the aging man affecting more and more men with increasing age. The normal adult prostate reaches a plateau at a weight of approximately $20 \mathrm{~g}$ at age 30 years [2]. After this, the weight remains stable till age about 50 years when the prostate starts increasing in size at an average of $0.5-0.8 \mathrm{~g} /$ year so that by age 80 years, almost $90 \%$ men have evidence of $\mathrm{BPH}[3]$

$\mathrm{BPH}$ is a cause for urinary symptoms that may range from mild to distressing in different individuals [4]. The symptoms also may not correlate with the size of the prostate with even small prostate causing severe symptoms while large prostates may remain asymptomatic being diagnosed incidentally or when complications develop [5]. BPH first develops in the periurethral transition zone of the gland and because of the presence of the capsule, the pressure is transmitted to the urethra causing the various symptoms [6]. The various symptoms resulting from BPH are together referred to as "prostatism." These include those due to obstructive pathology, namely, loss of urinary stream force, intermittency, and incomplete voiding hesitancy [7].

Uroflowmetry is now a simple and cheap modality allowing quick evaluation of the obstructive component and forms an important part of the urology clinic [8]. However, uroflowmetry suffers from the drawback in that it does not distinguish between BPH and other causes of obstructive lower urinary tract symptoms like urethral strictures and a more elaborate urodynamic study may be required for differentiation [9]. The aims and objectives the present study was to evaluate patients of BPH preoperatively and identify those who would benefit from surgery, to evaluate outcome of surgery for BPH with respect to symptomatic and objective improvement of patients, and to compare the results of different surgeries for BPH being done different hospitals at Bhopal, which included transurethral resection of the prostate (TURP), transurethral incision of prostate (TUIP)/bladder neck incision (BNI), and Freyer's prostatectomy.

\section{METHODS}

The present study was carried out in the Department of Surgery RKDF Medical College, MIMS, CIMS, Adarsh Hospital, MKM Stone and Urology Centre, Bhopal. Patients presenting to the surgery outpatient department with symptoms of obstruction, namely, weak urinary stream, frequency hesitancy, intermittency, urgency, nocturia, etc., were included in the study. Some of the subjects included were patients presenting during emergency timings with complaints of retention of urine or occasionally other symptoms. (Such patients required catheterization for relief of obstruction). 
All such patients were examined fully including a digital rectal examination (DRE). Patients who had enlargement of prostate, as examined by DRE [10], and whose symptoms were suspected to be due to such enlargement were investigated further.

The American Urological Association (AUA) Symptom Index questionnaire was administered to all such patients. They were also evaluated by ultrasound examination and patients having BPH on ultrasound (USG) also were further evaluated by uroflowmetry [11]. Patients with obstructive symptoms and also documented obstruction on uroflowmetry (flow rates $<15 \mathrm{ml} / \mathrm{s}$ ) were finally included in the study, such patients underwent operation for relief of symptoms TUIP/BNI, TURP, or Freyer's prostatectomy [12].

In the post-operative period, the patients remained catheterized for 3-4 days (cases of TUIP/BNI/TURP) or 5-6 days in case of Freyer's prostatectomy. Patients were called for follow-up at 1 month after the date of operation when they were again evaluated by means of physical examination AUA symptom score findings at USG examination and uroflowmetry [13].

Transabdominal ultrasonography [14] was done. The examination was done preoperatively with a full bladder to evaluate the prostate size, the condition of the bladder, the ureters, and the kidneys after evaluation with a full urinary bladder, the patients voided urine and were reevaluated for an estimate of the post-void residual urine volume. Similar examination carried out when the patients reported for post-operative follow-up [15]. The prostatic volume remaining after prostatectomy (in TURP cases) compared with the pre-operative prostatic weight [16]. Any improvement in residual urine volume and any resolution of changes in the upper urinary tract noted. Uroflowmetry done at the MKM Stone and Urology Centre, Bhopal.

\section{RESULTS}

The present study was conducted with the aim to evaluate outcome of surgery for BPH with respect to symptomatic and objective improvement of patients and to compare the different modalities of surgery (TURP, TUIP/BNI, and Freyer's prostatectomy) for BPH being done at different hospitals.

Fifty patients were evaluated using AUA symptom score, USG, and uroflowmetry. The criteria included in uroflowmetry were maximum urinary flow rate $(\mathrm{Qmax})$ and average flow rates $(\mathrm{w})$.

\section{DISCUSSION}

The maximum no. of patients were in the age group of 51-60 years. Maximum patients preoperatively were in the AUA score range 2130 (mean score - 21.02). Postoperatively, the maximum number of patients was in the score range 10 (mean 8.96), retrospectively, a maximum of 27 patients had a Qmax between 6 and $10 \mathrm{ml} / \mathrm{s}$ (mean Qmax $9.56 \mathrm{ml} / \mathrm{s}$ ). Postoperatively, 21 patients had Qmax $>20 \mathrm{ml} / \mathrm{s}$ while another 20 patients had Qmax $16-20 \mathrm{ml} / \mathrm{s}$. Together 41 patients now had Qmax in the "normal" range (mean Qmax $19.59 \mathrm{ml} / \mathrm{s}$ ). Similarly, Qav was $<5 \mathrm{ml} / \mathrm{s}$ in a maximum no. of 35 patients preoperatively (mean Qav - $4.37 \mathrm{ml} / \mathrm{s}$ ). Postoperatively, Qav was $6-10 \mathrm{ml} / \mathrm{s}$ in 28 patients (mean Qar- $9.79 \mathrm{~m} / \mathrm{s}$ )

Considering the various operations, TURP was done in 31 patients, Freyer's prostatectomy in 15 patients while TUIP/BNI was done in 4 patients. Mean pre-operative AUA scores in TURP group were 21.48 while in the group of patients undergoing Freyer's prostatectomy and TUIP/BNI. It was 21.08 and 17.5, respectively.

Retrospectively, the mean AUA scores for the patients who underwent TURP were 9.29, for patients who had Freyer's prostatectomy, it was 7.86, and for the TUIP/BNI group, it was 10. Change in AUA scores was thus 12.03 for TURP, while it was 13.33 and 10 for Freyer's prostatectomy and TUIP/BNI, respectively.
Table 1a: AUA symptom score distribution (pre-operative)

\begin{tabular}{lll}
\hline AUA score & No. of patients & Percentage \\
\hline$<10$ & 1 & 2 \\
$11-20$ & 21 & 42 \\
$21-30$ & 25 & 50 \\
$30-35$ & 3 & 6 \\
\hline
\end{tabular}

AUA: American Urological Association.

Table 1b: AUA symptom score distribution (post-operative)

\begin{tabular}{lll}
\hline AUA score & No. of patients & Percentage \\
\hline$<10$ & 33 & 66 \\
$11-20$ & 17 & 34 \\
$21-30$ & - & - \\
$30-35$ & - & - \\
\hline
\end{tabular}

AUA: American Urological Association.

Mean pre-operative Qmax for the TURP group was $9.35 \mathrm{ml} / \mathrm{s}$. For patients who later underwent Freyer's prostatectomy, mean Qmax was $8.64 \mathrm{ml} / \mathrm{s}$ and for those who later had TUIP/BNI, it was $14.55 \mathrm{~m} / \mathrm{s}$. Mean post-operative Qmax for the three groups was $20.06 \mathrm{ml} / \mathrm{s} .20 .69 \mathrm{ml} / \mathrm{s}$ and $19.68 \mathrm{ml} / \mathrm{s}$, respectively. Change in Qmax was thus $10.77 \mathrm{ml} / \mathrm{s}$ for TURP $9.98 \mathrm{ml} / \mathrm{s}$ for Freyer's prostatectomy and $19.68 \mathrm{ml} / \mathrm{s}$ for TUIP/ BNI, respectively.

Mean overall 8 AUA score (change in AUA score) was $12.03 \mathrm{ml} / \mathrm{s}$. Mean overall and Qmax change in Omar was $10.77 \mathrm{ml} / \mathrm{s}$. Mean overall and Qav (change in Qav) was $6.19 \mathrm{ml} / \mathrm{s}$.

\section{CONCLUSION}

Uroflowmetry was a simple assessment tool easy to learn and use. It was also inexpensive and formed a useful extension to clinical examination providing objective evidence of obstruction [17]. It also helped to indirectly quantity the severity of obstruction. Symptom severity did not correlate with prostate size. Small prostates caused symptoms in the severe range also while even large prostates sometimes caused little symptoms [18]. Prostatic weight correlated well with the maximum urinary flow rates with an inverse relationship [19]. There was significant improvement in symptoms with all the three operations for BPH, namely, TURP, TUIP/BNI, and Freyer's prostatectomy [20]. Both maximum and average urinary flow rates ( $Q$ max and Qav) were improved by all the three surgeries However, TURP and Freyer's prostatectomy showed greater improvement as compared to TUIP/BNI [21]. Improvement in symptoms was not dependent on the pre-operative prostatic weight. Extent of post-operative improvement depended on the pre-operative status of the patient [22]. Assessment by uroflowmetry, especially for maximum urinary flow rates (Qmax), was highly beneficial in quantifying the obstructive pathology in our BPH patients [23]. Combination of AUA scoring, USG, and uroflowmetry helped us document improvement in our $\mathrm{BPH}$ patients and compared it favorably with other studies [24].

Thus, we conclude that all patients suspected to have urinary symptoms because of BPH should have a thorough clinical examination along with AUA [25] symptom scoring, USG, and uroflowmetry [26]. This would help in proper evaluation of patients as well as in exclusion of unnecessary surgical interventions keeping in mind the various intricacies involved in the management of patients of $\mathrm{BPH}$ [27].

\section{AUTHORS' CONTRIBUTIONS}

All the authors have contributed to the preparation and editing of this research article.

\section{REFERENCES}

1. Adams PH. Prostatism and prostatectomy, the value of urine flow rate measurement in the preoperative assessment for operation. J Urol 
1977;117:70-1

2. Abrams PH, Farrar DJ, Tumer Warwick RT, Whiteside CG, Feneley RC. The results of prostatectomy a symptomatic and urodynamic analysis of 152 patients. J Urol 1979;121:640-842.

3. Barry MJ, Cockett AT, Hoigrewe HL, McConnell JD, Sihelink SA, Winfield HN. Relationship of symptoms of prostatism to commonly used physiological and anatomical measures of the severity of benign prostatic hyperplasia. J Urol 1993;150:351-8.

4. Castro JE, Griffiths HJ, Shackman R. Significance of signs and symptoms of benign prostatic hyperplasia. Br Med J 1969;2:598-601.

5. Derrett S, Paul C, Herbison P. Prospective evaluation of the effects of prostatectomy on symptoms and quality of life. $\mathrm{N} Z$ Med J 2001;114:276-9.

6. Dorfinger P, Bruskewitz R, Lensen KM, Iversen P, Madsen PO. Predictive value of low maximum flow rate in benign prostatic hyperplasia. Urology 1986;27:569-73.

7. Drach GW, Steinbronn DV. Clinical evaluation of patients with prostatic obstruction: Correlation of flow rates with voided, residual or total bladder volume. J Urol 1986;135:737-40.

8. Groshar D, Koritny ES, Embon OM, Sazbon A, Frenkel A. Radionuclide measurement of bladder emptying rate Simultaneous comparison with urinary flow rate obtained by uroflowmetry. Clin Nucl Med 1988;13:365-5.

9. Herbison AE, Fraundorder MR, Walton JK. Association between symptomatology and uraflowmetry in benign prostatic hypertrophy. $\mathrm{Br}$ J Urol 1988;62:427-30.

10. Jensen KM, Jorgensen JB, Morgensen P, Bille Brahe NE. Some clinical aspects of uroflowmetry in elderly males A population survey. Scand $\mathrm{J}$ Urol Nephrol 1986;20:93-9.

11. Jensen KM, Jorgensen JB, Morgensen P. Reproducibility of uroflowmetry variables in elderly males. Urol Res 1985;13:237-9.

12. Jensen KM, Jorgensen JB, Morgensen P. Relationship between urinary flow curve patterns and symptomatology in elderly males. Scand J Urol Nephrol Suppl 1987;104:69-71.

13. Jensen KM, Jorgensen JB, Morgensen P UrodynamicSin prostatism. I. Prognostic value of uroflowmetry. Scand J Urol Nephrol Suppl 1988;114:63-71.

14. Jensen KM, Jorgensen JB Morgensen P. Urodynamics in prostatism II. Prognostic value of pressure flow study combined with stop flow test.
Scand J Urol Nephrol Suppl 1988;114:72-7.

15. Jorgensen JB, Jensen KM, Bille Brahe NE, Morgensen P. Uroflowmetry in asymptomatic elderly males. Br J Urol 1986;58:390-5.

16. Mbaba AN, Ogolodom MP, Abam R, Nengi A, Chiegwu HU, Bakre AK, et al. Ultrasonographic and retrograde urethrographic assessment of aetiological factors of bladder outlet obstruction in adult males in port Harcourt, Nigeria. Health Sci J 2019;13:680.

17. Ko DS, Fenster HN, Chambers K, Sullivan LD, Jens M, Goldenberg SL. The correlation of multichannel urodynamic pressure flow studies and AUA symptom index in the evaluation of BPH. J Urol 1995;154:402-3.

18. Lidgi S, Moskovitz B, Groshar D, Embon OM, Levin DR, Sazbon A. Preoperative prediction of results of prostatectomy by a symptom score and radionuclide uroflowmetry Eur Urol 1989;16:97-100.

19. Borges RC, Tobias-Machado M, Gabriotti EN, et al. Post-radical prostatectomy urinary incontinence: Is there any discrepancy between medical reports and patients' perceptions? BMC Urol 2019;19:32.

20. McLoughlin J, Abel PD, Williams S. Symptoms versus flow rates Vs urodynamics in selection of patients for prostatectomy. Br J Urol 1990;66:303.

21. Nielsen KT, Christensen MM, Madsen PO, Bruskewitz RC. Symptom analysis and uroflowmetry 7 years after transurethral resection of the prostate. J Urol 1989;142:1251-3.

22. Ogreid P, Kloster SE, Guleng R, Skjeggestand O, Mestad OF. Noninvasive evaluation of the enlarged prostate preliminary results. Scand J Urol Nephrol Suppl 1988;110:319-28.

23. Roehrborn CG, Chinn HK, Fulgham PF, Simpkins KL, Peters PG. The role of transabdominal ultrasound in the preoperative evaluation of patients with benign prostatic hypertrophy. J Urol 1986;135:1190-3.

24. Roehrborn CG. Objective and subjective response criteria to diagnose benign prostatic hyperplasia. Eur Urol 1993;24:12.

25. Roos NP, Ramsay EW. A population based study of prostatectomy outcomes associated with differing surgical approaches. J Urol 1987; $137: 1184-8$.

26. Shimizu K, Takahashi Y, Sekihara T, Imai K, Yamanaka H, Mayuzumi T, et al. Study of voiding disturabces in elderly males Ill Analysis of flow rates and patterns in uroflowmetric studies Comparison between children, young adults and elderly men. Hinyokika Kiyo 1987;33:521-6.

27. Schafer W. Principles and clinical application of advanced urodynamic analysis of voiding function. Urol Clin N Am 1980;17:176-533. 